International Journal of Engineering \& Technology, $7(4.10)(2018) 661-665$
International Journal of Engineering \& Technology
SPC
Website: www.sciencepubco.com/index.php/IJET
Research paper

\title{
Slip Effects on MHD Convective Two-Phase Particulate Suspension Flow in a Convergent Channel
}

\author{
S Ramprasad $^{1 *}$, S.H.C.V.Subba Bhatta ${ }^{2}$ and B.Mallikarjuna ${ }^{3}$ \\ ${ }^{I}$ Department of Mathematics,M S Ramaiah Institute of Technology, Bangalore,India,sadhurp@ gmail.com \\ ${ }^{2}$ Department of Mathematics,M S Ramaiah Institute of Technology, Bangalore,India,shcvsb@gmail.com \\ ${ }^{3}$ Department of Mathematics,B.M.S.College of Engineering, Bangalore,India,mallikarjuna.jntua@ gmail.com \\ *Corresponding author E-mail:sadhurp@gmail.com
}

\begin{abstract}
In this article an attempt has been made to dscuss the velocity and temperature slip effects on MHD convective two phase particulate suspension flow in a convergent channel with viscous dissipation. The non dimensionalised governing equations are solved using RungeKutta shooting method.The results obtained are represented graphically for various emerging parameters. The skin friction coefficient and Nusselt number are obtained and validated with existing results.It is found that with an increase in velocity slip parameter the velocity of the fluid increases.The fluid phase temperature decreases with an increase in temperature slip parameter.
\end{abstract}

Keywords: Convergent Channel; fluid particle suspension, MHD; slip effects; Two-phase flows;

\section{Introduction}

Flows through oblique walls like convergent or divergent channels have got lot of engineering applications in aerospace engineering, bio mechanical engineering, chemical engineering etc. First Jeffrey [1] and Hamel[2] proposed a model to study flow through convergent and divergent channels. Many investigators [3]to[7] have considered different physical properties related to Jeffrey Hamel flow and investigated flow characteristics .These investigators used no slip boundary conditions at the walls. First Dorreppal [8]

considered Jeffrey-Hamel flow and fluid is allowed to slip along the walls of the channel in both convergent and divergent cases and solved analytically. Later few reserchers [9] to[13] introduced the velocity slip/temperature and velocity slip and studied velocity and temperature profiles in convergent or divergent channels. The concept of two-phase flows is highly useful in understanding of various industrial and engineering problems. Two-phase flows are frequently used in compact heat exchangers, nuclear reactors and small-sized refrigeration systems. Many researchers [14-15] studied two-phase flows through channels and pipes analytically and numerically. Flow of fluid with suspended particles has various applications to MHD generators, solid propellant rockets etc.Usha et al [16] Recently numerical study of two-phase flow of particulate suspension in non uniform channel has been discussed by Ramprasad et al [17] . Many researchers concentrated on single phase flow through convergent or divergent channels. So for reported in the literature no consulted effort has been made to study velocity and temperature slip effects on MHD convective twophase particulate suspension flows in a convergent channel with viscous dissipation keeping in view of the above facts the present work has been proposed.

\section{Formulation of the Problem}

Consider a steady, viscous in compressible buoyancy driven magneto hydrodynamic two phase particulate suspension flow in a convergent channel. The velocity and temperature slip condition has been implemented on the flow field taking into the account of viscous dissipation. The governing equations are

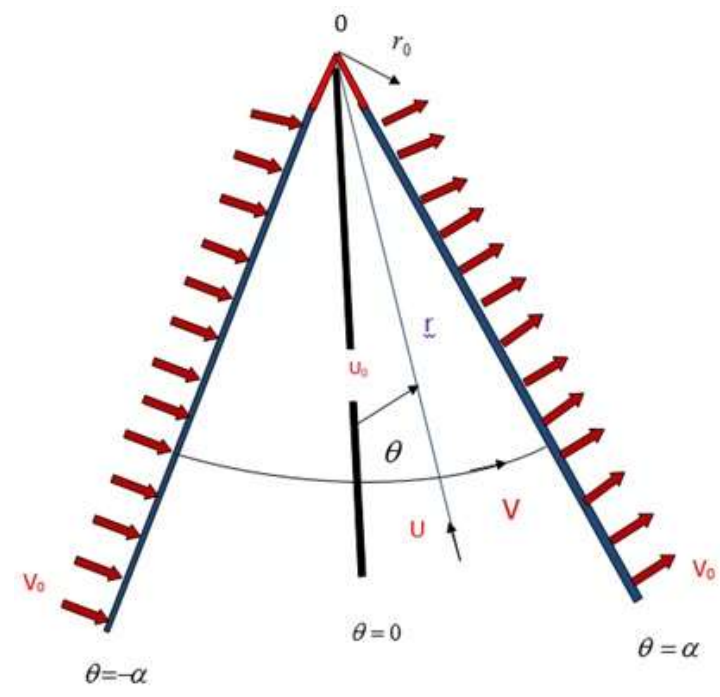

Fig. 1: Physical geometry

For fluid phase

$$
\frac{\partial}{\partial r}\left(r u_{1}\right)+\frac{\partial v_{1}}{\partial \theta}=0
$$




$$
\begin{gathered}
\left(u_{1} \frac{\partial u_{1}}{\partial r}+\frac{v_{1}}{r} \frac{\partial u_{1}}{\partial \theta}-\frac{v_{1}^{2}}{r}\right)=-\frac{1}{\rho} \frac{\partial p}{\partial r}+v\left[\left(\frac{\partial^{2} u_{1}}{\partial r^{2}}+\frac{1}{r} \frac{\partial u_{1}}{\partial r}+\frac{1}{r^{2}} \frac{\partial^{2} u_{1}}{\partial \theta^{2}}\right)-\frac{u_{1}}{r^{2}}+\frac{2}{r^{2}} \frac{\partial v_{1}}{\partial \theta}\right] \\
+\frac{\rho_{p}}{\rho} S\left(u_{1 p}-u_{1}\right)-\frac{\sigma H_{0}^{2} \mu_{e}^{2} u_{1}}{\rho}-g \beta T_{1} \\
\left(u_{1} \frac{\partial v_{1}}{\partial r}+\frac{v_{1}}{r} \frac{\partial v_{1}}{\partial \theta}+\frac{u_{1} v_{1}}{r}\right)=-\frac{1}{\rho r} \frac{\partial p}{\partial \theta}+v\left[\left(\frac{\partial^{2} v_{1}}{\partial r^{2}}+\frac{1}{r} \frac{\partial v_{1}}{\partial r}+\frac{1}{r^{2}} \frac{\partial^{2} v_{1}}{\partial \theta^{2}}\right)-\frac{v_{1}}{r^{2}}+\frac{2}{r^{2}} \frac{\partial u_{1}}{\partial \theta}\right] \\
+\frac{\rho_{p}}{\rho} S\left(v_{1 p}-v_{1}\right) \\
u_{1} \frac{\partial T_{1}}{\partial r}+\frac{v_{1}}{r} \frac{\partial T_{1}}{\partial \theta}=\frac{k}{\rho c_{p}}\left(\frac{1}{r} \frac{\partial}{\partial r}\left(r \frac{\partial T_{1}}{\partial r}\right)+\frac{1}{r^{2}} \frac{\partial^{2} T_{1}}{\partial \theta^{2}}\right)+\frac{\rho_{p} c_{m}}{\tau_{T} \rho c_{p}}\left(T_{1 p}-T_{1}\right)+ \\
\frac{\mu}{\rho c_{p}}\left\{\left[2\left(\frac{\partial u_{1}}{\partial r}\right)^{2}+\frac{1}{r}\left(\frac{\partial v_{1}}{\partial \theta}+\frac{u_{1}}{r}\right)^{2}\right]+\left[r \frac{\partial}{\partial r}\left(\frac{v_{1}}{r}\right)+\frac{1}{r} \frac{\partial u_{1}}{\partial \theta}\right]^{2}\right\}
\end{gathered}
$$

\section{For particle phase}

$\frac{\partial}{\partial r}\left(r u_{1 p}\right)+\frac{\partial v_{1 p}}{\partial \theta}=0$

$\left(u_{1 p} \frac{\partial u_{1 p}}{\partial r}+\frac{v_{1 p}}{r} \frac{\partial u_{1 p}}{\partial \theta}-\frac{v_{1 p}{ }^{2}}{r}\right)=-\frac{1}{\rho_{p}} \frac{\partial p}{\partial r}+S\left(u_{1}-u_{1 p}\right)-g \beta T_{1 p}$

$\left(u_{1 p} \frac{\partial v_{1 p}}{\partial r}+\frac{v_{1 p}}{r} \frac{\partial v_{1 p}}{\partial \theta}+\frac{u_{1 p} v_{1 p}}{r}\right)=-\frac{1}{r \rho_{p}} \frac{\partial p}{\partial \theta}+S\left(v_{1}-v_{1 p}\right)$

$u_{1 p} \frac{\partial T_{1 p}}{\partial r}+\frac{v_{1 p}}{r} \frac{\partial T_{1 p}}{\partial \theta}=\frac{1}{\tau_{T}}\left(T_{1}-T_{1 p}\right)$

where $r, \theta$ Polar coordinates, $\alpha$ Angle of the channel, $v$ Kinematic viscosity, $\mu$ coefficient of viscosity, $\rho$ density of the fluid , $\sigma$ conductivity of the fluid, $\mu_{e}$ magnetic permeability of the fluid, $H_{0}$ magnetic field intensity, $u_{1}$ fluid phase velocity, $u_{1 p}$ particle phase velocity, $S$ drag coefficient of the interaction for the force exerted by one face on the other.

The boundary conditions are

$u_{1}(0)=u_{0}, u_{1}(\theta= \pm \alpha)=-s_{1} \frac{\partial u_{1}(\theta= \pm \alpha)}{\partial \theta} ; \quad u_{1 p}(\theta= \pm \alpha)=0$

$T_{1}(\theta)=T_{w}-t_{1} \frac{\partial T_{1}(\theta)}{\partial \theta}, T_{1 p}=T_{w_{p}}$ at $\theta= \pm \alpha$

Introducing the following dimensionless variables

$u_{1}=\frac{u_{0} r_{0} F(\theta)}{r} ; u_{1 p}=\frac{u_{0} r_{0} G(\theta)}{r} ; v_{1}=\frac{v_{0} r_{0}}{r} ; v_{1 p}=\frac{v_{p_{0}} r_{0}}{r} ; h=\frac{T_{1}}{T_{w}} ; H=\frac{T_{1 p}}{T_{w_{p}}}$

Equations (1) - (8) are reduces to

$$
\begin{aligned}
& F^{\prime \prime \prime}+2 \operatorname{Re} F F^{\prime}-R F^{\prime \prime}+A B\left(G^{\prime}-F^{\prime}\right)+\left(4-M^{2}\right) F^{\prime}-\frac{G r}{\operatorname{Re}} h^{\prime}=0 \\
& G^{\prime \prime}-2 \frac{\operatorname{Re}}{R} G G^{\prime}-\frac{B}{R}\left(F^{\prime}-G^{\prime}\right)-\frac{G r}{\operatorname{Re} R} H^{\prime}=0
\end{aligned}
$$

$h^{\prime \prime}-R \operatorname{Pr} h^{\prime}+A \beta_{t} \gamma \operatorname{Pr}(H-h)+\operatorname{Pr} E c\left[3 F^{2}+4 \frac{R^{2}}{\mathrm{Re}^{2}}+F^{\prime 2}-4 \frac{R}{\mathrm{Re}} F^{\prime}\right]=0$

$H^{\prime}-k(h-H)=0$
Associated boundary conditions are

$$
\begin{aligned}
& F(\theta)=-s 1 F^{\prime}(\theta) ; G( \pm \alpha)=0 ; h( \pm \alpha)=1-t 1 h^{\prime}( \pm \alpha) \\
& H( \pm \alpha)=1 ; F(0)=-1
\end{aligned}
$$

Where $\mathrm{F}$ is fluid phase velocity, $\mathrm{G}$ is particle phase velocity, $\beta_{t}$ is fluid particle interaction parameter for temperature, $\mathrm{s} 1$ is the slip parameter for velocity,tl is the slip parameter for temperature, $h$ is fluid phase temperature, $\mathrm{H}$ is particle phase temperature.Reynolds number $=\operatorname{Re}=\frac{u_{0} r_{0}}{v} \quad$ Cross flow Reynolds number $=\mathrm{R}=\frac{v_{0} r_{0}}{v}$;

Ratio of the densities of the particle and fluid phase $=A=\frac{\rho_{p}}{\rho}$ Fluid particle interaction parameter for velocity $=B=\frac{s r^{2}}{v} ;$ Magnetic parameter $=M^{2}=\frac{\sigma H_{0}{ }^{2} \mu_{e}{ }^{2} r^{2}}{\rho v} ;$ Grashof number $=G r=\frac{\beta g T_{w} r^{3}}{v^{2}} ;$ Prandtl number $=\operatorname{Pr}=\frac{\mu c_{p}}{k} ;$ Eckert number $=E c=\frac{u_{0}^{2} r_{0}^{2}}{r^{2} c_{p} T_{w}}$

\section{Skin friction Coefficient and Nusselt Number}

In non-dimensional form

$C_{f}=\frac{1}{\operatorname{Re}} f^{\prime}( \pm \alpha)$ and $N u=-h^{\prime}( \pm \alpha)$

\section{Results and Discussion}

Eqns. (10) to (13) with subject to conditions (14) are solved numerically using shooting technique (Mallikarjuna et al [18, 19 and 20]. To validate the method, present results are compared with Ramprasad et al. [17] as shown in Table-1 and it is found to be very good agreement. Velocity and temperature profiles are discussed in this section. For computational purpose the governing parameter values fixed as $\mathrm{A}=1, \mathrm{R}=0.5, \mathrm{Re}=0.5, \mathrm{M}=1.5, \mathrm{Gr}=5$,

$\operatorname{Pr}=0.71, s 1=0.5, t 1=0.5, E c=0.5, \alpha=\frac{\pi}{6}, \gamma=0.5, B=1$.

From fig. 2 it is observed that an enhancement in $\mathrm{M}$, the fluid velocity accelerates in the left half of the channel and reverse behavior is observed in right half of the channel. The decrement of fluid velocity in the right half of the channel is due to Lorentz force, which opposes the flow direction.It is clear from fig 3, an increase in $\mathrm{Re}$, the fluid velocity decreases for $\mathrm{Re}=0.2,0.7,0.9$ consistently but for $\operatorname{Re}=0.5$, the fluid velocity increase in left half of the channel and decreases in the right half of the channel. Fig 4 elucidates that an increase in $\mathrm{R}$, the velocity of the fluid phase decreases in the left half of the channel and reverse behavior is noted in the right half of the channel. From fig 5 it is clear that an increase in Gr, the velocity of the fluid phase increases in the left half of the channel and it decreases in the right half of the channel. It is interesting to note that the buoyancy effect is more near left wall compared with that of the right wall.In order to illustrate the influence of slip parameter s1 on the fluid velocity fig 6 is plotted. An increment in s1, enhances the fluid velocity in entire channel. For $s 1=0$, no slip condition there is no change in the velocity of the fluid phase near walls of the channel.In order to discuss the influence of different governing parameters on particle phase velocity figures $7-10$ are plotted.From fig.7 it is observed that an increase in $\mathrm{M}$, the particle velocity increases in the channel upto $\alpha=0.3$. From $\alpha=0.3$ to the right boundary reversal behavior is observed. It can be seen from fig 8 that the particle phase velocity decreases rapidly for small values of $\mathrm{Re}$, i.e $\mathrm{Re}=0.2,0.5,0.7$ indicating the particle phase is highly viscous and flow is laminar. 
When $\operatorname{Re}=0.9$, the particle velocity increases. This behavior is seen in Ramprasad et al [17].From fig 9 it can be noted that the particle velocity decreases for $\mathrm{R}=0.5,2.5,3.5$. Further when $\mathrm{R}=5.0$ the particle velocity shoots up. This indicates that for large values of cross flow Reynolds number, the particle phase viscosity increases there by the cross flow dominates and the particle velocity increases. It is clear from fig 10 an increase in $\mathrm{Gr}$, the particle phase velocity increases, the convection cells start growing from both sides of walls and shows significant increase in the particle velocity in the mid region of the channel. Fig 11 depicts that, as Ec increases the fluid temperature also increases. The same behavior is noted in fig 12 for an increase in Pr. From fig 13 it is concluded that the fluid phase temperature decreases as slip parameter increases.From fig 14, 15 it is clear that an increase in Ec,Pr the particle phase temperature decreases.

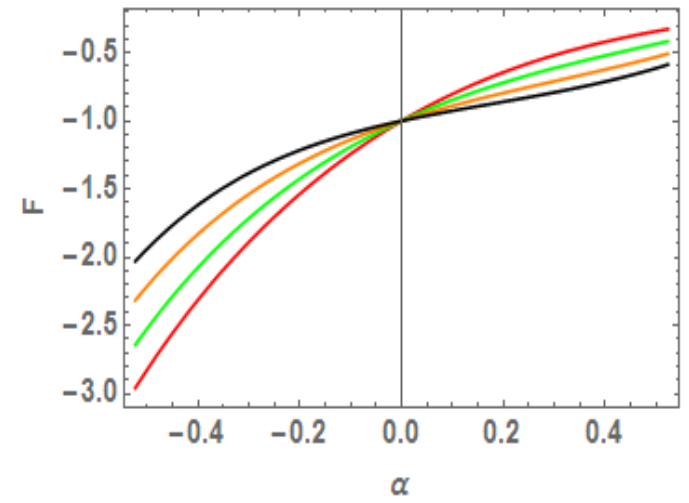

$-M=1.5$

- $M=2.0$

$-M=2.5$

$-M=3.0$

Fig. 2: variation of $F$ with $M$

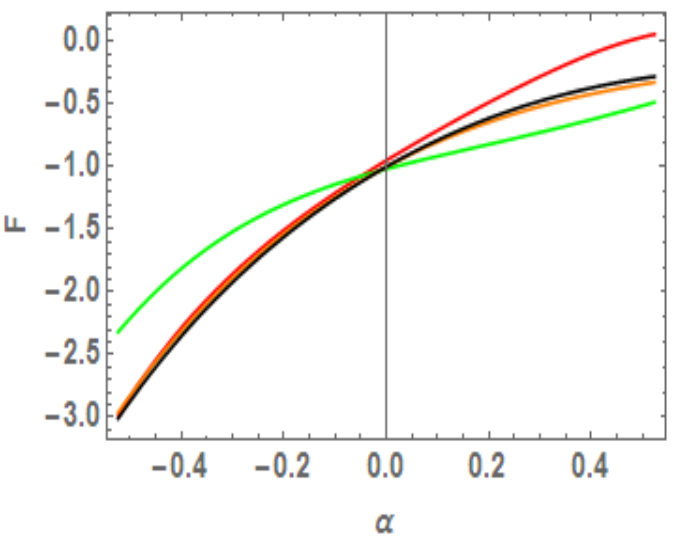

- $\operatorname{Re}=0.2$

- $\mathrm{Re}=0.5$

- $\operatorname{Re}=0.7$

- $\mathrm{Re}=0.9$

Fig. 3: variation of $F$ with $\mathrm{Re}$

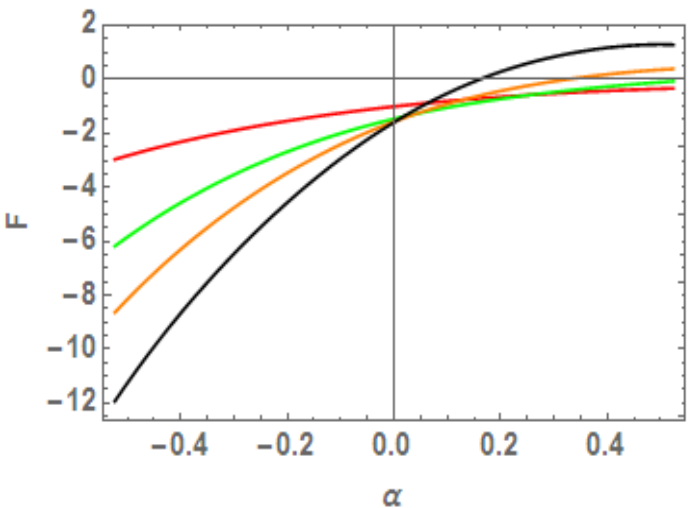

Fig. 4: variation of $F$ with $R$

- $\mathrm{R}=2.5$

- $\mathrm{R}=3.5$

- R=5.0

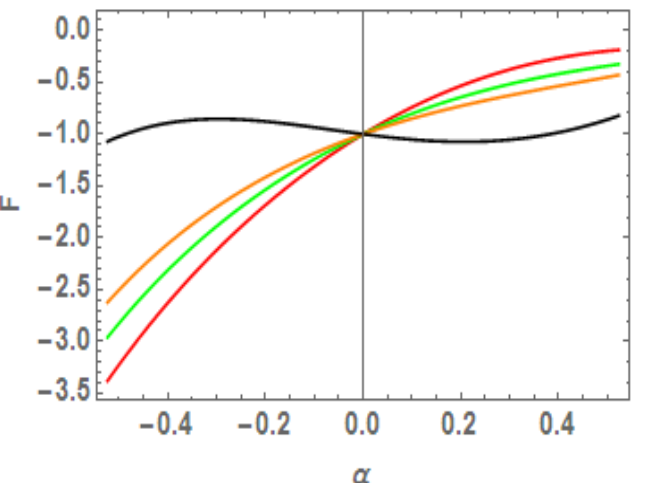

- $\mathrm{Gr}=3.0$

- $\mathrm{Gr}=5.0$

- $\mathrm{Gr}=7.0$

- $\mathrm{Gr}=9.0$

Fig. 5: variation of $\mathrm{F}$ with $\mathrm{Gr}$

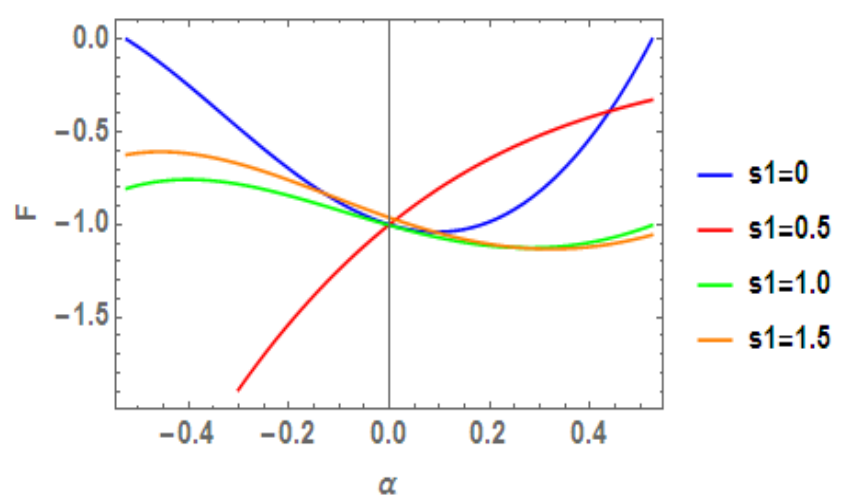

Fig. 6: variation of $F$ with s1

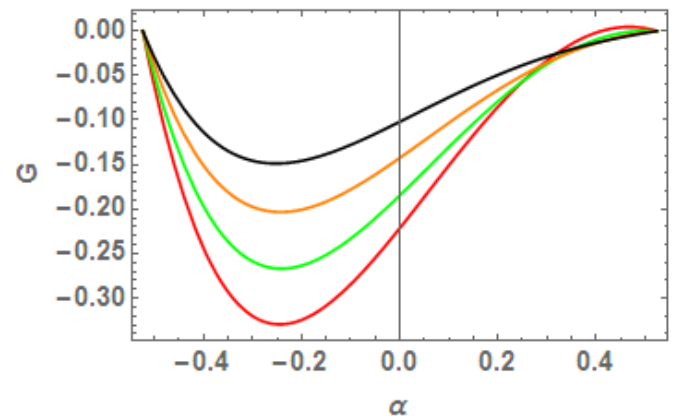

- $M=1.5$

- $M=2.0$

$M=2.5$

$-M=3.0$

Fig. 7: variation of $\mathrm{G}$ with $\mathrm{M}$

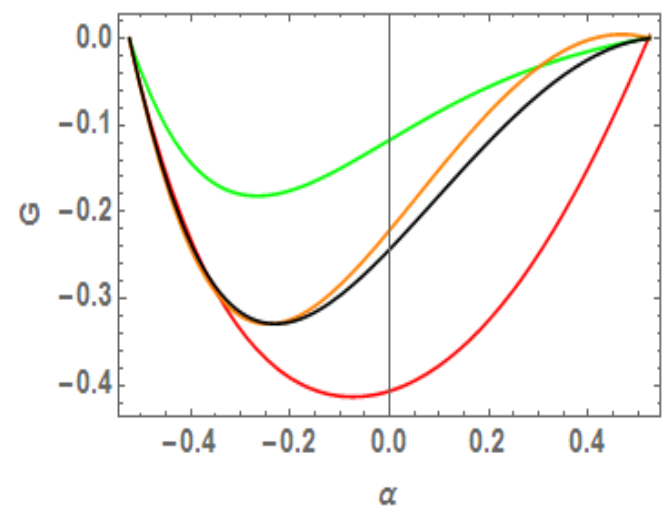

- $\mathrm{Re}=0.2$

- Re $=0.5$

- $\mathrm{Re}=0.7$

Fig. 8: variation of $\mathrm{G}$ with $\mathrm{Re}$ 


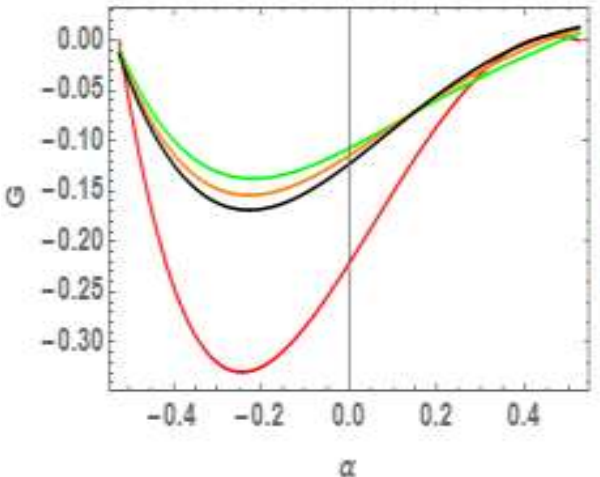

Fig. 9: variation of $\mathrm{G}$ with $\mathrm{R}$

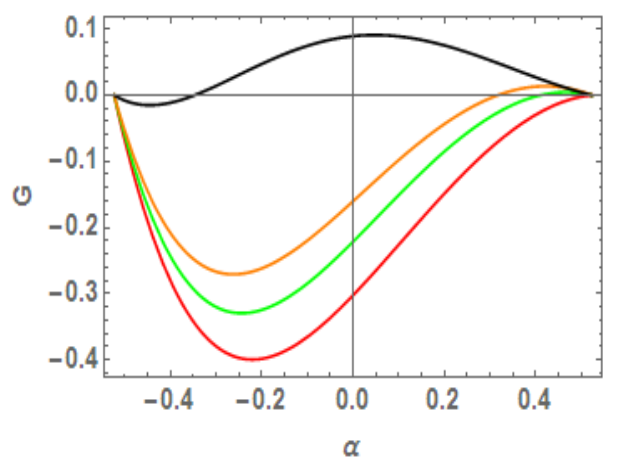

Fig. 10: variation of $\mathrm{G}$ with $\mathrm{Gr}$

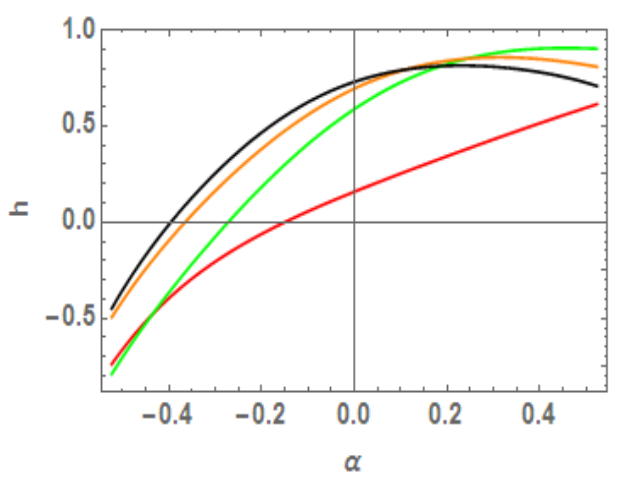

Fig. 11: variation of $h$ with Ec

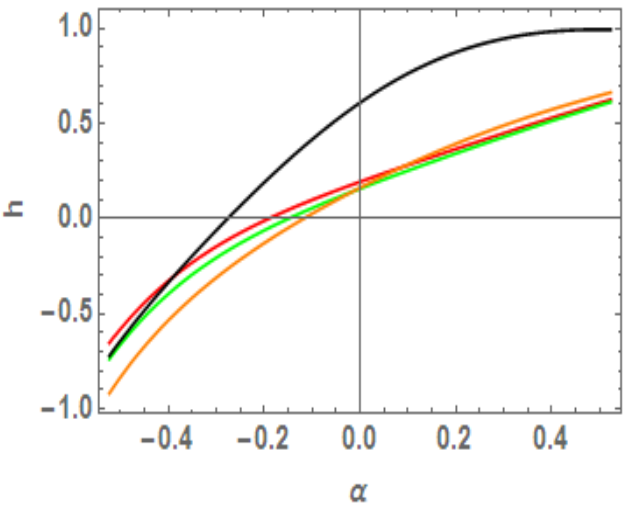

Fig. 12: variation of $h$ with $P r$
- $\mathrm{Gr}=7.0$

- Gr=9.0

- Ec=0.5

- Ec=1.5

- $\mathrm{Ec}=3.0$

- Ec=6.0

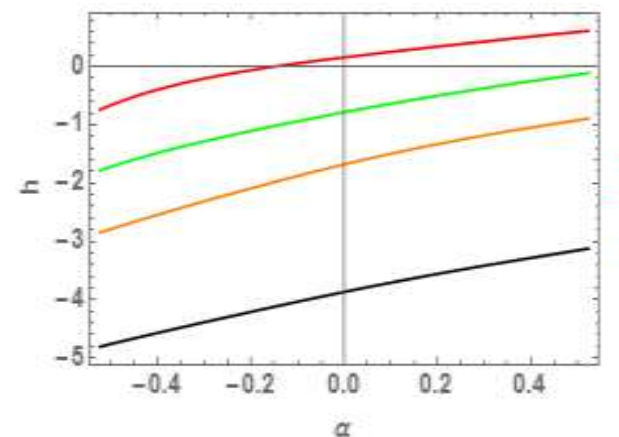

$-\mathrm{t} 1=0.5$

$-\mathrm{t}=1.0$

$\mathrm{H}=1.5$

$-\mathrm{t} 1=3.0$

Fig. 13: variation of $\mathrm{f}$ with $\mathrm{t} 1$

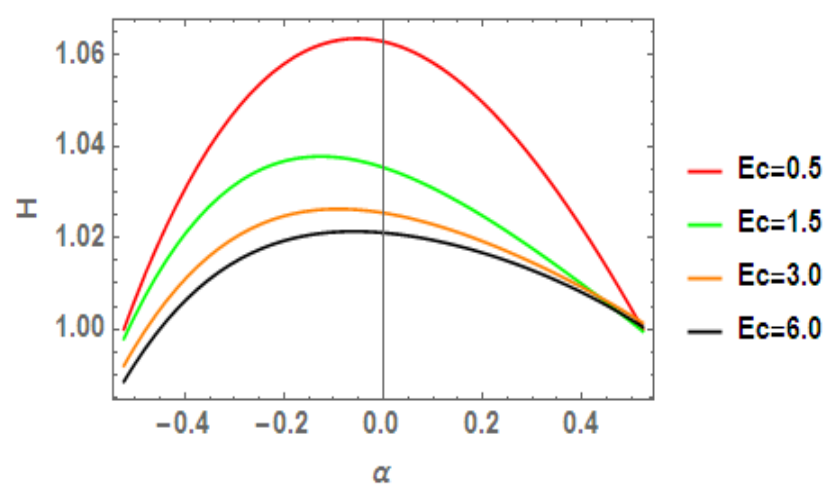

Fig. 14: variation of $\mathrm{H}$ with $\mathrm{Ec}$

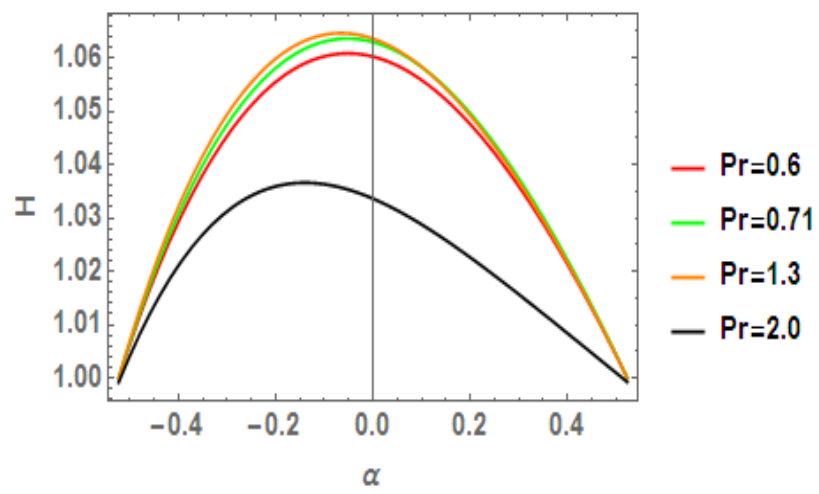

Fig. 15: variation of $\mathrm{H}$ with $\mathrm{Pr}$

\section{Conclusions}

- With an increase in M, the velocities of both phases increase in left half of the channel and depreciates in the right half of the channel.

- For small values of Re,an increase in Re the velocities of fluid as well as particle phases decreases.This indicates medium is highly viscous.

- An increase in $\mathrm{Gr}$, the fluid velocity increases near the left boundary and decreases near the right boundary where as the particle velocity increases in entire channel due to thermal buoyancy force.

- An increase in velocity and temperature slip parameters separation near the walls increases and temperature fluid phase decreases.

- An increase in Ec,Pr fluid temperature increases where as the particle temperature decreases. 
Table 1: Comparison results of skin friction coefficient $\left(F^{\prime}(\alpha)\right)$ for $\gamma=0, \quad \beta=1, s 1=0, t 1=0, E c=0, \beta_{t}, k=0 ., \quad M=0, \quad G r=0, \operatorname{Pr}=0, \mathrm{Q}=0$, $\alpha=\frac{\pi}{6}$

\begin{tabular}{|l|l|l|l|l|l|l|}
\hline $\mathrm{R}$ & $\mathrm{Re}$ & $\beta$ & $\begin{array}{l}\text { Ramprasad } \\
\text { et.al } \\
{[17]}\end{array}$ & $\begin{array}{l}\text { Ramprasad } \\
\text { et.al } \\
{[17]}\end{array}$ & Present & Present \\
\hline 1 & 1 & 1 & -3.01181 & 4.40023 & -3.01125 & 4.41278 \\
\hline 3 & & & -2.27677 & 6.57888 & -2.28097 & 6.58771 \\
\hline 5 & & & -1.95449 & 9.48694 & -1.95881 & 9.49390 \\
\hline 8 & & & -1.81670 & 14.7735 & -1.82035 & 14.7780 \\
\hline 1 & 3 & & -3.23754 & 4.58254 & -3.23717 & 4.59433 \\
\hline & 5 & & -3.45904 & 4.76762 & -3.45880 & 4.77874 \\
\hline & 1 & 1 & -3.05541 & 4.43305 & -3.05442 & 4.45791 \\
\hline & & 2 & -3.22663 & 4.56492 & -3.22508 & 4.63639 \\
\hline & & 3 & -3.04792 & 4.42570 & -3.04088 & 4.42749 \\
\hline
\end{tabular}

\section{References}

[1] G. B. Jeffery (1915), "The two dimensional steady motion of a viscous fluid", Philos. Mag. , 6, 455-465.

[2] Hamel,G (1916), "Spiralformige Bewgungen Zaher Flussigkeiten.”,Jahresbericht der DeutschenMath.Vereinigung, 25, 34-60.

[3] Terril, R.M (1965), "Slow Laminar Flow in a Converging or Diverging Channel with Suction at One Wall and Blowing at the Other Wall", ZAMP, 16, 306-312.

[4] Sinha Roy J,Nayak P (1982), "Steady two dimensional incompressible laminar visco-elastic flow in a converging and diverging channel", Acta Mechanica , 43, 129-136.

[5] Sparrow, E.M, Ruiz, R, Azevedo L.F.A (1988), "Experiments and numerical investigation of natural convection in convergent vertical channels", International Journal of Heat and Mass Transfer, 31, 907-915.

[6] [Yilmaz "OZT"URK,Adil AKYATAN, Erol SENOCAK (1998), "Slowflow of the Reiner-Rivlin fluid in a coverging or diverging channel with Suction and Injection", Tr. J. of Engineering and Environmental Science, 22, 179 -183.

[7] Serdar Baris (2003), "Flow of a second grade visco-elastic fluid in a porous converging channel", Turkish Journal of Eng. Env. Sci, 27

[8] Dorreppal, J.M. Erol SENOCAK (1993), "Slip flow in converging and diverging channels", Journal of Engineering Mathematics , 27, 343- 356.

[9] Syed Tauseef Mohyud-Din, Umar Khan ,Naveed Ahmed, Waseem Sikander (2015), "A Study of Velocity and Temperature Slip Effects on Flow of Water Based Nanofluids in Converging and Diverging Channels", Int. J. Appl. Comput. Math, 1, 569-587.

[10] Khan, U., Ahmed, N, Zaidi, Z.A, Asadullah, M, Mohyud-din (2015), "Effects of velocity slip and temperature jump on Jeffery Hamel flow with heat transfer", Engineering science and technology: an international journal

[11] Amir Moradi, Ahmed Alsaedi and Tasawar Hayat (2015), “ Investigation of Heat transfer and viscous dissipation effects on the Jefferey- Hamel flow of Nanofluids", Thermal Science , 19, 563-578.

[12] Reza Hosseini,Sadesh Poozesh and Saeed Dinarvand (2012), “ MHD flow of an incompressible viscous fluid through convergent or divergent channels in presence of a high magnetic field", Journal of Applied Mathematics,Hindawi Publishing Corporation, Article ID 157067.

[13] Mir Asadullah, umar khan, Naveed Ahmed, Raheela Manzoor, Syed Tauseef (2013), " MHD flow of a Jeffery fluid in converging and diverging channels", International Journal of Modern Mathematical Sciences ,6, 92-106.

[14] Chamkha A.J. (1995), "Hydromagnetic two-phase flow in a channel", International Journal of Engineering Science, 33, 437-446.

[15] Siva Kumar Reddy Cherlo, Sreenath Kariveti, and S. Pushpavanam (2010), “ Experimental and Numerical Investigations of Two-Phase (Liquid-Liquid)Flow Behavior in Rectangular Microchannels", Ind. Eng. Chem. Res, 49, 893-899.

[16] Usha, R, Senthilkumar, S and Tulapurkara, E.G. (2006), "Numerical study of particulate suspension flow through wavy-walled channels", International Journal for numerical methods in fluid, 51, 235-259.

[17] Ramprasad, S, Subba Bhatta, S.H.C.V. Mallikarjuna, B and Srinivasacharya D (2017), "Two-phase particulate suspension flow in convergent and divergent channels: A Numerical Model”, Interna- tional Journal of Applied and Computational Mathematics, 3, 843858 .

[18] Mallikarjuna, B, Rashad, A.M. Chamkha A.J, and Hariprasad Raju S (2016), "Chemical reaction effects on MHD convective heat and mass transfer flow past a rotating vertical cone embedded in a variable porosity regime", Afrika Mathematika, 27, 645-665.

[19] Mallikarjuna, B, Rashad, A.M. Hussein, A.K. and Hariprasad Raju, S (2016), "Transpiration and thermophoresis effects on non-Darcy convective flow over a rotating cone with thermal radiation", Arabian Journal for science and Engineering, 41, 4691-4700.

[20] Mallikarjuna, B, Rashidi,M.M, Hariprasad Raju, S (2017), "Influence of nonlinear convection and thermophoresis on heat and mass transfer from a rotating cone to fluid flow in porous medium", Thermal Science,21(6B), 2781-2793. 